\title{
O TRABALHO DO ASSISTENTE SOCIAL NA EDUCAÇÃO BÁSICA EM SALVADOR
}

\section{Ingrid Barbosa Silva ${ }^{1}$ \\ Adriana Freire Pereira Ferriz ${ }^{2}$}

Resumo: $O$ artigo apresenta uma análise acerca das condições de trabalho profissional do assistente social no âmbito da política de educação, especificamente na educação básica na cidade de Salvador. O objetivo central da pesquisa foi conhecer e analisar as condições de trabalho dos assistentes sociais nos espaços sócio-ocupacionais vinculados à educação básica em Salvador. A metodologia utilizada contemplou a realização de três entrevistas com assistentes sociais da rede pública e privada de educação básica. Os resultados apontam que há uma concentração de profissionais atuando em escolas particulares confessionais, com foco na avaliação social para concessão de bolsas de estudo. Na rede pública de ensino é quase inexistente a atuação do profissional de Serviço Social e, por isso, podemos afirmar que há um déficit de assistentes sociais na educação básica em instituições públicas em Salvador.

Palavras-chave: Serviço Social; Educação básica; Condições de Trabalho; Trabalho profissional.

\footnotetext{
${ }^{1}$ Universidade Federal da Bahia/Serviço Social, Salvador, Brasil. E-mail: ingridzinha.01@hotmail.com. ${ }^{2}$ Universidade Federal da Bahia/Serviço Social, Salvador, Brasil. E-mail: adriana.ferriz@ufba.br.
} 